Supplement of Atmos. Chem. Phys., 21, 10273-10293, 2021

https://doi.org/10.5194/acp-21-10273-2021-supplement

(c) Author(s) 2021. CC BY 4.0 License.

(c) (1)

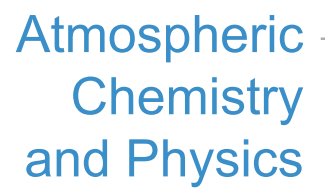

Atmospheric

and Physics

Supplement of

\title{
Characterization of primary and aged wood burning and coal combustion organic aerosols in an environmental chamber and its implications for atmospheric aerosols
}

Amir Yazdani et al.

Correspondence to: Satoshi Takahama (satoshi.takahama@epfl.ch) and Imad El Haddad (imad.el-haddad@psi.ch)

The copyright of individual parts of the supplement might differ from the article licence. 


\section{S1 Experimental set-up}

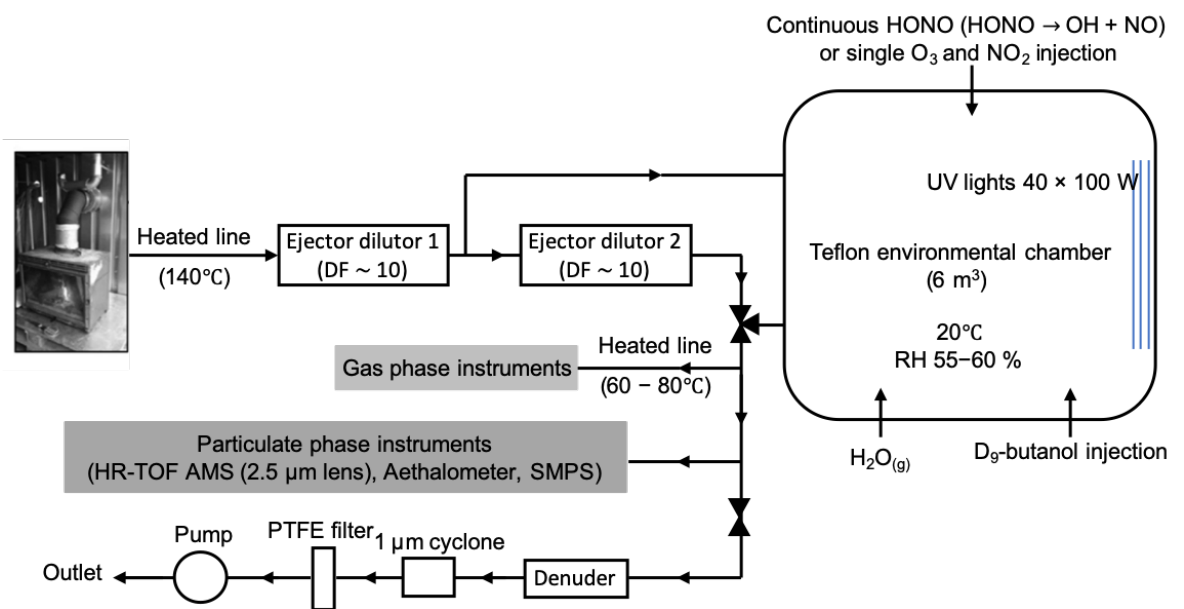

Figure S1. Schematic of the experimental set-up used for photo-oxidation and dark oxidation of biomass burning and coal combustion emissions.

\section{S2 Blank subtraction}

As can be seen from Fig. S2, the blank subtraction algorithm used in this work permits better identification of organic FG absorbances that are either overlapping with PTFE absorbances (e.g. the carbonyl peak) or are completely masked by them (e.g. the levoglucosan and organonitrate peaks). In addition, water vapor and $\mathrm{CO}_{2}$ bands are eliminated with this method.

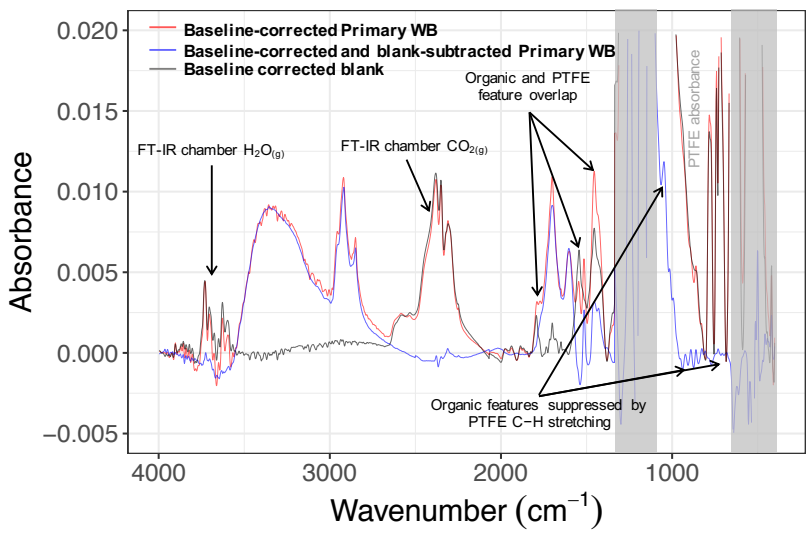

Figure S2. Comparison between baseline-corrected (red) and blank-subtracted baseline-corrected spectra (blue) of WB aerosols. 


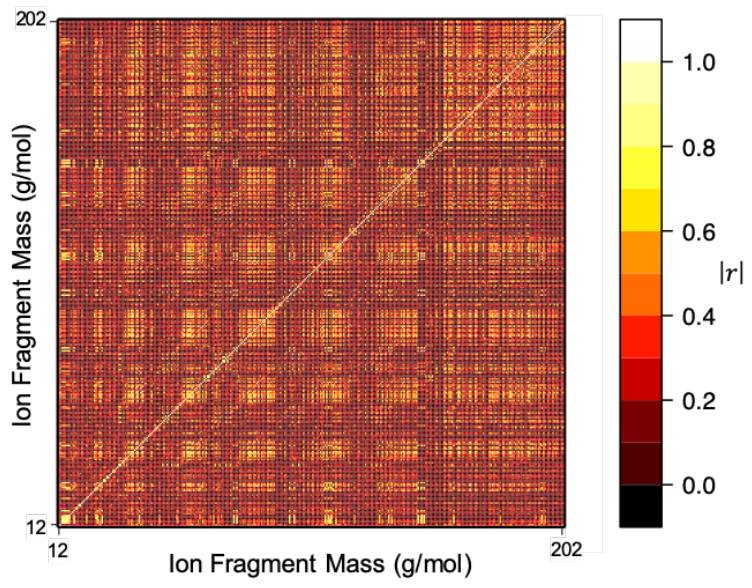

Figure S3. Heat map of correlation matrix of mass fragments.

\section{S3 Dimentionality reduction}

\section{S4 The MIR and AMS spectra and chemical composition of the chamber experiments}

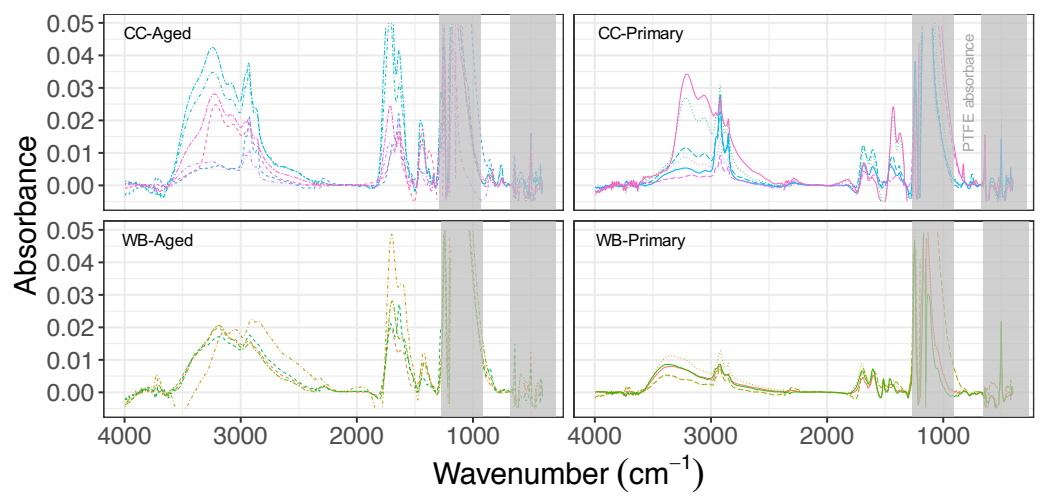

WB_OH_1 $\mathrm{P}$

WB-OH_-P

WB_OH_2_A

NB-OH_3-

WB_NO3_1-P

WB-NO3-1

CC_OH_1-A

CC_OH_2-P

CC-OH_- $2-\mathrm{A}$

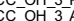

CCNO3_1-A

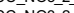

CC_NO3-2-A

CC_NO3_3_A

Figure S4. Baseline-corrected spectra of wood burning (WB) and coal combustion (CC) emissions separated by emission source and aerosol type. 

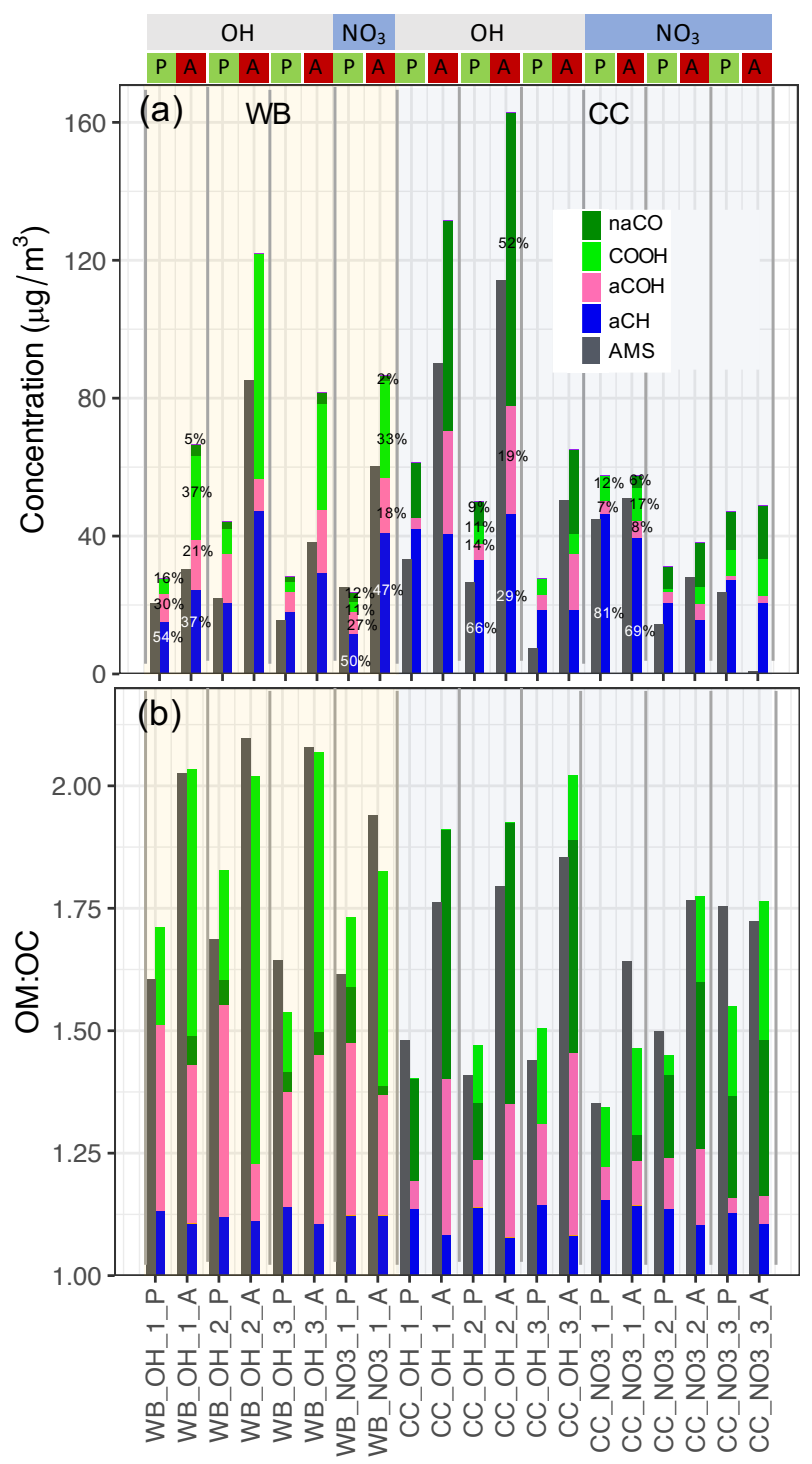

Figure S5. (a) Bar plot comparing AMS and MIR OA concentration estimates separated by functional group. The emission pairs (primary and aged emissions of the same experiment) are grouped by vertical lines. The type of aerosol (P: primary, A: aged), emission source (WB and $\mathrm{CC}$ ), and oxidant used for aging ( $\mathrm{OH}$ : hydroxyl radical, $\mathrm{NO}_{3}$ : nitrate radical) are indicated for each experiment. The percentage of each FG to total OA mass before and after aging is indicated for some experiments. (b) Bar plot comparing AMS OM:OC estimates with that of MIR spectroscopy separated by contribution of each functional group. 


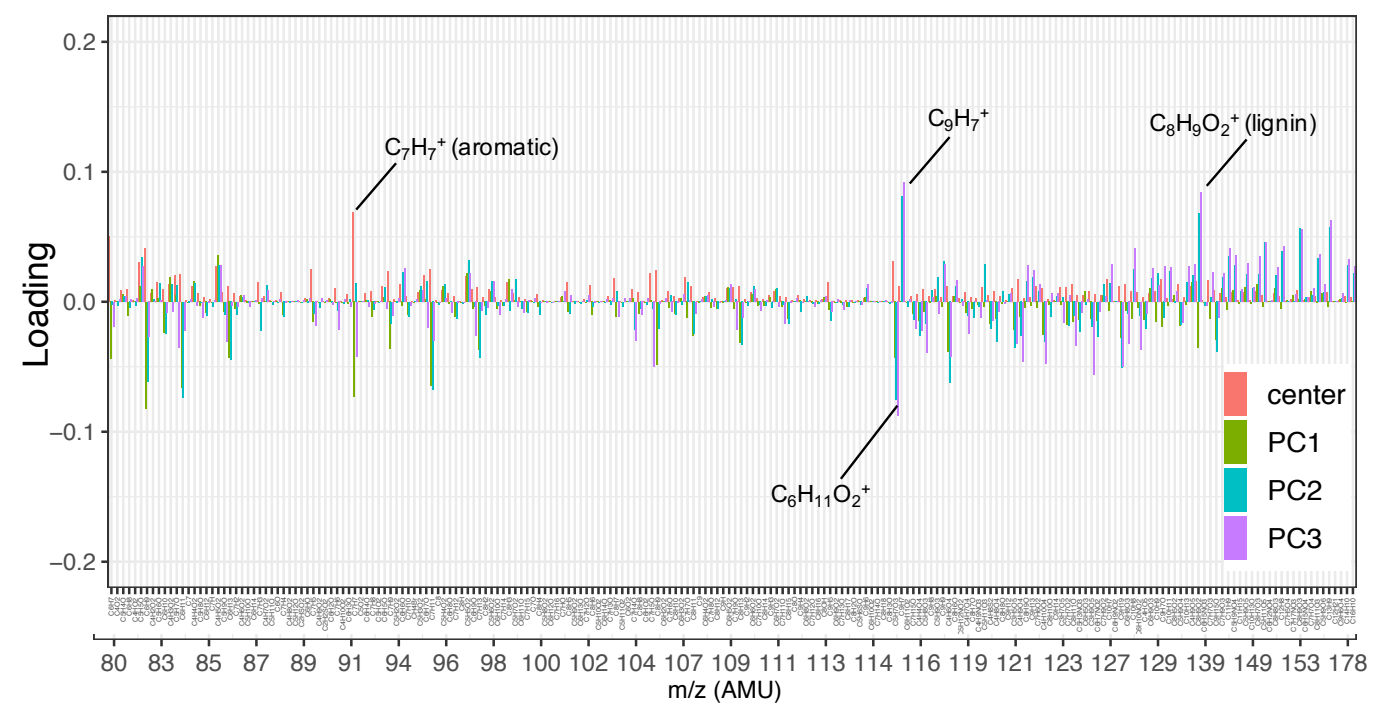

Figure S6. Loadings of the first three principal components and the normalized mean AMS mass spectrum (from $\mathrm{m} / \mathrm{z} 80$ to $\mathrm{m} / \mathrm{z} 202$ ). Fragment ions with high positive/negative loadings are indicated by their formula.
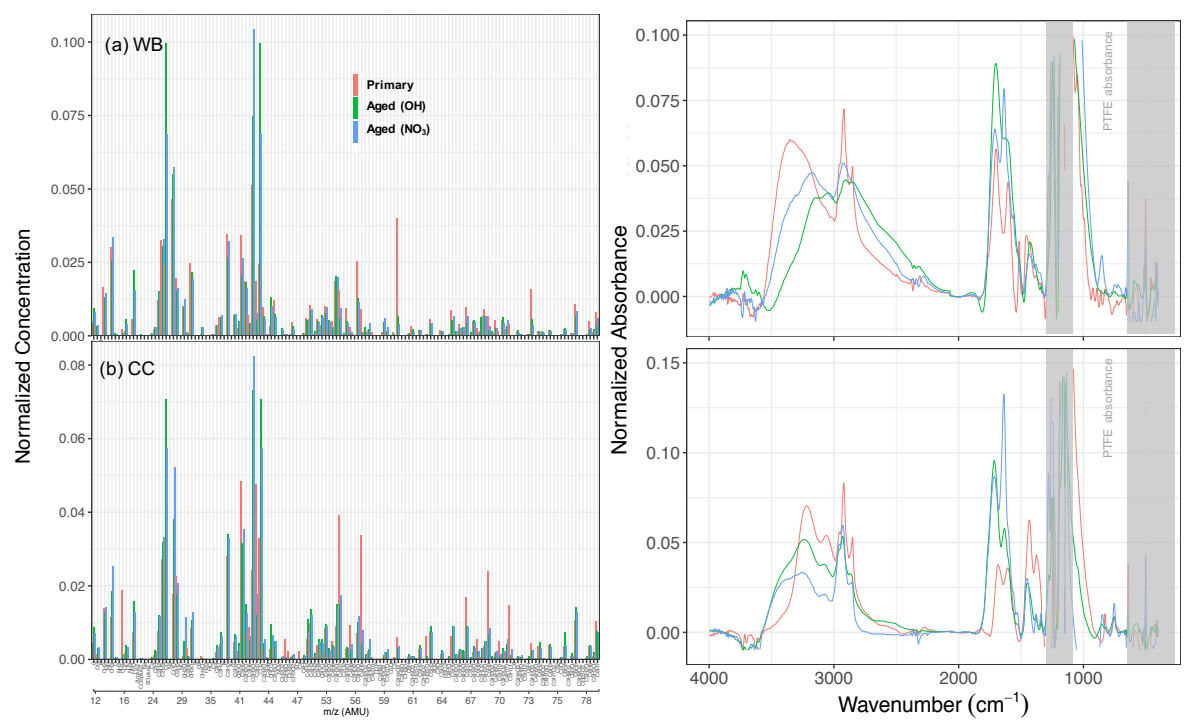

Figure S7. AMS normalized mass spectra (shown up to $\mathrm{m} / \mathrm{z} 80$ ) averaged during filter sampling for 20 minutes (left) and normalized midinfrared spectra (Euclidean norm) of WB (a) and CC (b) on filter. 

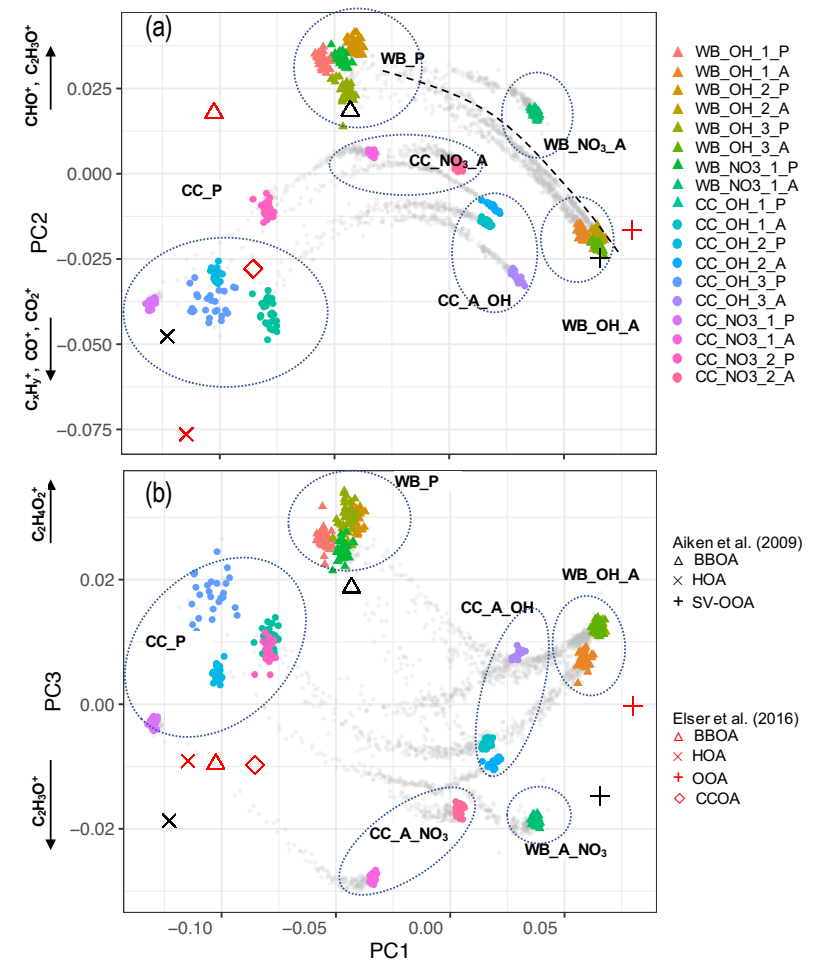

Figure S8. Biplots of PC2-PC1 (a), PC3-PC1 (b). The AMS measurements corresponding to filter sampling periods are color coded. The oxidation trajectories out of filter sampling periods are illustrated by gray dots. The clusters of samples based on their fuel and oxidant are indicated by dashed circles. 


\section{S5 Aromatics and Polycyclic aromatic hydrocarbons (PAHs)}

In this work, the following AMS fragment ions attributed to aromatics are quantified (Bruns et al., 2015; Pavia et al., 2008): $10 \mathrm{C}_{6} \mathrm{H}_{5}{ }^{+}, \mathrm{C}_{7} \mathrm{H}_{7}{ }^{+}, \mathrm{C}_{7} \mathrm{H}_{5} \mathrm{O}^{+}, \mathrm{C}_{8} \mathrm{H}_{5} \mathrm{O}_{2}{ }^{+}, \mathrm{C}_{6} \mathrm{H}_{6}{ }^{+}, \mathrm{C}_{6} \mathrm{H}_{6} \mathrm{O}^{+}, \mathrm{C}_{8} \mathrm{H}_{9}{ }^{+}, \mathrm{C}_{8} \mathrm{H}_{10}{ }^{+}, \mathrm{C}_{8} \mathrm{H}_{8}{ }^{+}, \mathrm{C}_{7} \mathrm{H}_{7} \mathrm{O}^{+}$, and $\mathrm{C}_{7} \mathrm{H}_{8} \mathrm{O}^{+}$. The summed concentration of these fragments is correlated with the MIR out-of-plane aromatic $\mathrm{CH}$ peak absorbance at $754 \mathrm{~cm}^{-1}\left(R^{2}=\right.$ 0.70; Fig. S9). This correlation is considerably stronger than that of AMS total OA mass concentration with the MIR out-ofplane aromatic $\mathrm{CH}$ peak absorbance $\left(R^{2}=0.49\right)$, suggesting a physical connection between the AMS fragments and the MIR absorbance at $754 \mathrm{~cm}^{-1}$. The mentioned aromatic fragments contribute up to $6 \%$ to the total OA mass. It is believed that oxygenated aromatics undergo fragmentation during electron impact ionization; thus, their contribution is possibly underestimated using AMS fragments.

From the PAH fragment ions suggested by Bruns et al. (2015) and Elser et al. (2016), $\mathrm{C}_{10} \mathrm{H}_{7}{ }^{+}, \mathrm{C}_{10} \mathrm{H}_{8}{ }^{+}, \mathrm{C}_{10} \mathrm{H}_{9}{ }^{+}, \mathrm{C}_{12} \mathrm{H}_{8}{ }^{+}$, $\mathrm{C}_{13} \mathrm{H}_{9}{ }^{+}, \mathrm{C}_{14} \mathrm{H}_{10}{ }^{+}, \mathrm{C}_{16} \mathrm{H}_{10}{ }^{+}$fragment ions were quantified in this work. The mentioned aromatic fragments contribute up to $3 \%$ to the total OA mass. However, the fragments quantified in this work are not complete and oxygenated PAHs are also believed to undergo fragmentation during electron impact ionization (McLafferty and Tureček, 1993); thus, their contribution is possibly underestimated.

Mid-infrared aromatic $\mathrm{CH}$ absorbances are, however, not significantly different between oxygenated and non-oxygenated aromatics and PAHs. The mid-infrared OOP peak absorbance normalized by total OA mass can be an indicator of relative contribution of aromatic $\mathrm{CH}$. This parameter is on average four times higher for $\mathrm{CC}$ aerosol compared to WB.

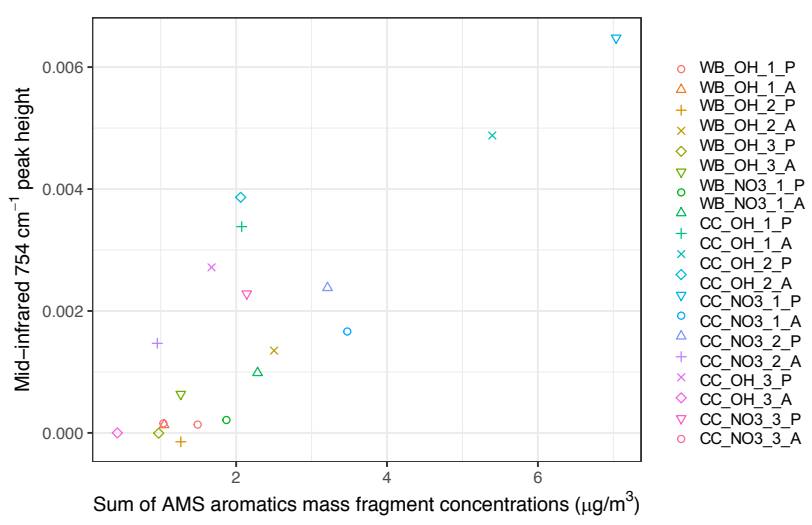

Figure S9. Scatter plot comparing MIR absorbance at $754 \mathrm{~cm}^{-1}$ (attributed the aromatic CH out-of-plane vibration) and sum of AMS fragment ions attributed to aromatics over the filter sampling periods for each experiment $\left(R^{2}=0.70\right)$. The corresponding fragments were taken from Bruns et al. (2015) and Pavia et al. (2008). 
In previous studies (e.g. Russell et al., 2009; Faber et al., 2017), the alcocol COH abundances (calculated using MIR spectra) were compared to the abundance of AMS fragment ions attributed to levoglucosan fragmentation $\left(\mathrm{C}_{2} \mathrm{H}_{4} \mathrm{O}_{2}{ }^{+}\right.$and $\left.\mathrm{C}_{3} \mathrm{H}_{5} \mathrm{O}_{2}{ }^{+}\right)$, often resulting in low correlation coefficients. Levoglucosan, however, absorbs at several specific frequencies in mid-infrared range $\left(860,890,920,950,990,1012\right.$, and $\left.1050 \mathrm{~cm}^{-1}\right)$ which are not observed for other compounds containing the aCOH group (Interference with other anhydrous sugars, monnasan and galactosan is possible; Fig. S10a). In addition to lack of these specific absorption other compounds usually have high abundance of non-alcohol FGs that dominate the spectra. As a results, the specific levoglucosan peaks, which become identifiable after blank subtraction, have been used in this study to quantify levoglucosan (an important tracer of biomass burning). By scaling the mentioned peaks in a pure levoglucosan MIR spectrum to that of WB samples, it can be seen that approximately $40 \%$ of the aCOH functional group in WB_OH_2_P (a primary WB sample having high concentration of levoglucosan) is due to levoglucosan (Fig. S10b). By using the same method, we estimate that levoglucosan is responsible for, on average, $20 \%$ of the aCOH group in primary WB aerosols and less than $10 \%$ in aged WB aerosols, suggesting levoglucosan degradation with aging (Hennigan et al., 2010). The specific levoglucosan absorbances in primary and aged CC aerosols are generally below detection limit of FT-IR (negative absorptions at peak in $860-1050 \mathrm{~cm}^{-1}$ region; Fig. S11), suggesting negligible amounts of levoglucosan in these samples.

40 The $\mathrm{C}_{2} \mathrm{H}_{4} \mathrm{O}_{2}{ }^{+}$fragment ion ( $\mathrm{m} / \mathrm{z} 60$ in unit mass resolution) in AMS spectrum is shown to be a tracer of levoglucosan (Aiken et al., 2009; Faber et al., 2017; Schneider et al., 2006) in spite of having interference from other molecules, such as long-chain carboxylic acids (Schneider et al., 2006). In order to calculate levoglucosan concentrations from AMS measurements, $0.3 \%$ of OA was subtracted from the $\mathrm{C}_{2} \mathrm{H}_{4} \mathrm{O}_{2}{ }^{+}$ion fragment signal (accounting for other molecules producing the same signal) and the remaining signal was called "levoglucosan-equivalent" concentration. The averaged "levoglucosan-equivalent" signal over the filter sampling periods is highly correlated to levoglucosan peak intensities in MIR spectra (Fig. S11).

The decrease in levoglucosan-equivalent AMS signal (on average $1.11 \mathrm{~h}^{-1}$ ) and FT-IR levoglucosan absorbances (on average $0.75 \mathrm{~h}^{-1}$ ) with aging are much more that what can be attributed solely to particle-phase wall losses with a rate constant on the order $0.2-0.3 \mathrm{~h}^{-1}$. 


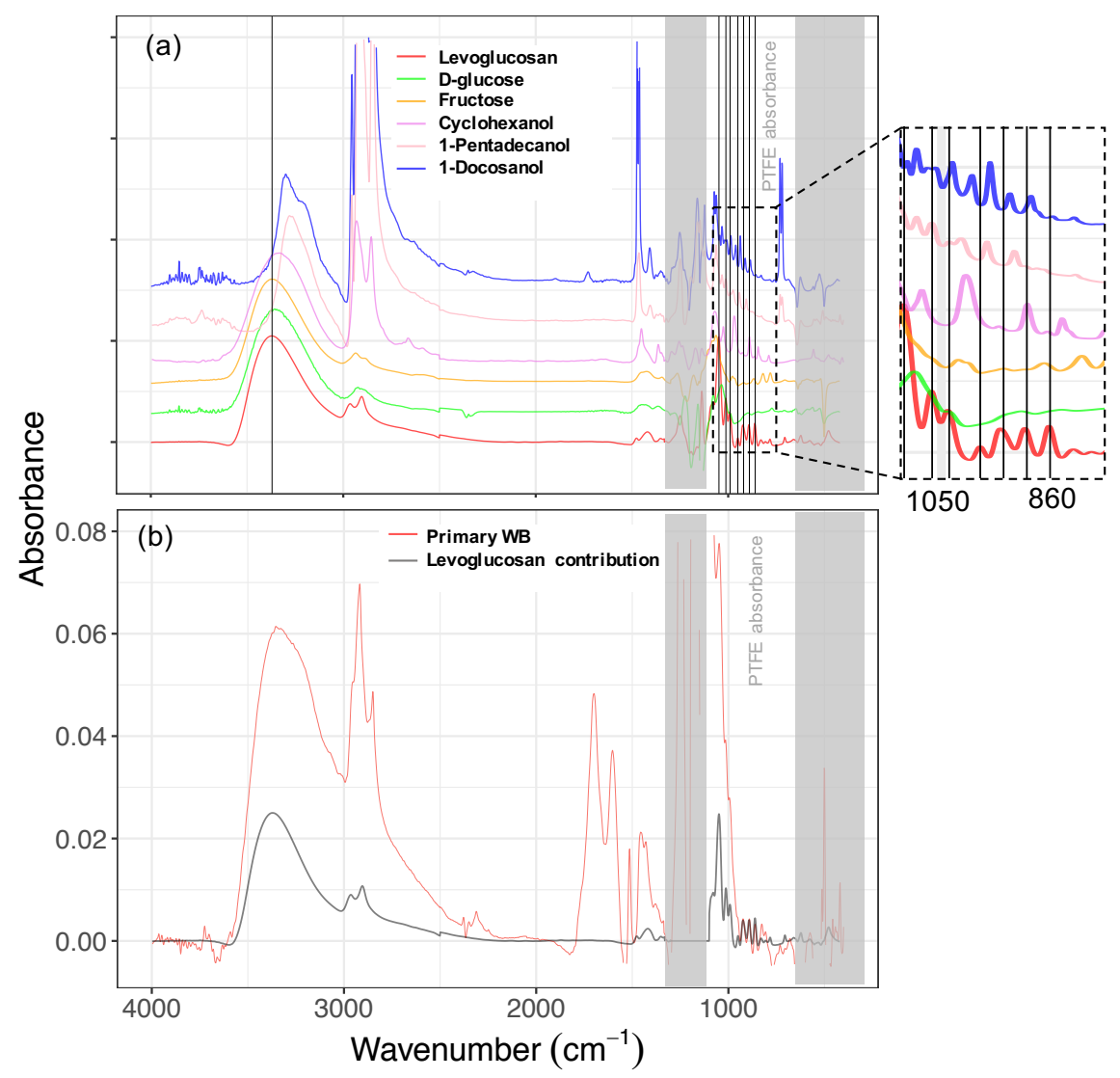

Figure S10. (a) Baseline corrected spectra of six different organic compounds containing the aCOH group (e.g. sugars, sugar derivatives, cyclic and straight-chain alcohols). Peak frequencies of levoglucosan are indicated by vertical lines $(860,890,920,950,990,1012$, and 1050 $\mathrm{cm}^{-1}$ ). (b) Baseline-corrected spectra of fresh wood burning (WB) aerosols and levoglucosan scaled based of its signature at 860-1050 $\mathrm{cm}^{-1}$. The contribution of levoglucosan to the fresh WB aCOH is estimated to be approximately $40 \%$ in this case (WB_OH_2_P). The spectra of d-glucose and fructose are taken from Ruthenburg et al. (2014). 


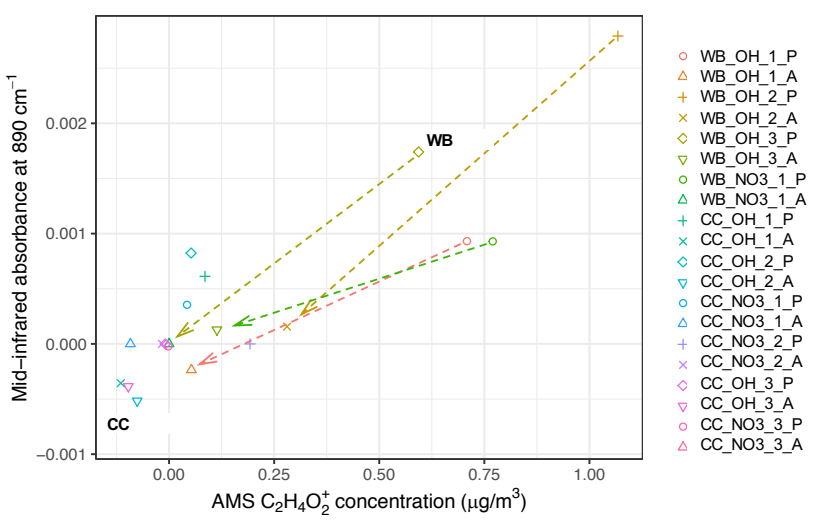

Figure S11. Scatter plot comparing the MIR absorbances attributed to levoglucosan and $\mathrm{AMS}_{2} \mathrm{H}_{4} \mathrm{O}_{2}{ }^{+}$fragment ion concentration averaged over the filter sampling periods $\left(R^{2}=0.76\right) .0 .03 \%$ of OA concentration is subtracted from $\mathrm{C}_{2} \mathrm{H}_{4} \mathrm{O}_{2}{ }^{+}$mass concentration to account for the non-levoglucosan sources (Aiken et al., 2009). Arrows show the change in levoglucosan with aging. 


\section{S7 Lignin signatures}

50 The peak at $1515 \mathrm{~cm}^{-1}$ is observed in lignin, WB aerosols, and coniferyl alcohol (a monolignol) due to aromatic ring stretching. A similar peak is observed in para-substituted compounds with a few $\mathrm{cm}^{-1}$ shift in the peak frequency from that of lignin. No similar peak is observed compounds without para substitutions. The methoxy peak at $2820 \mathrm{~cm}^{-1}$ is also relatively weak for lignin, coniferyl alcohol, and WB aerosols.

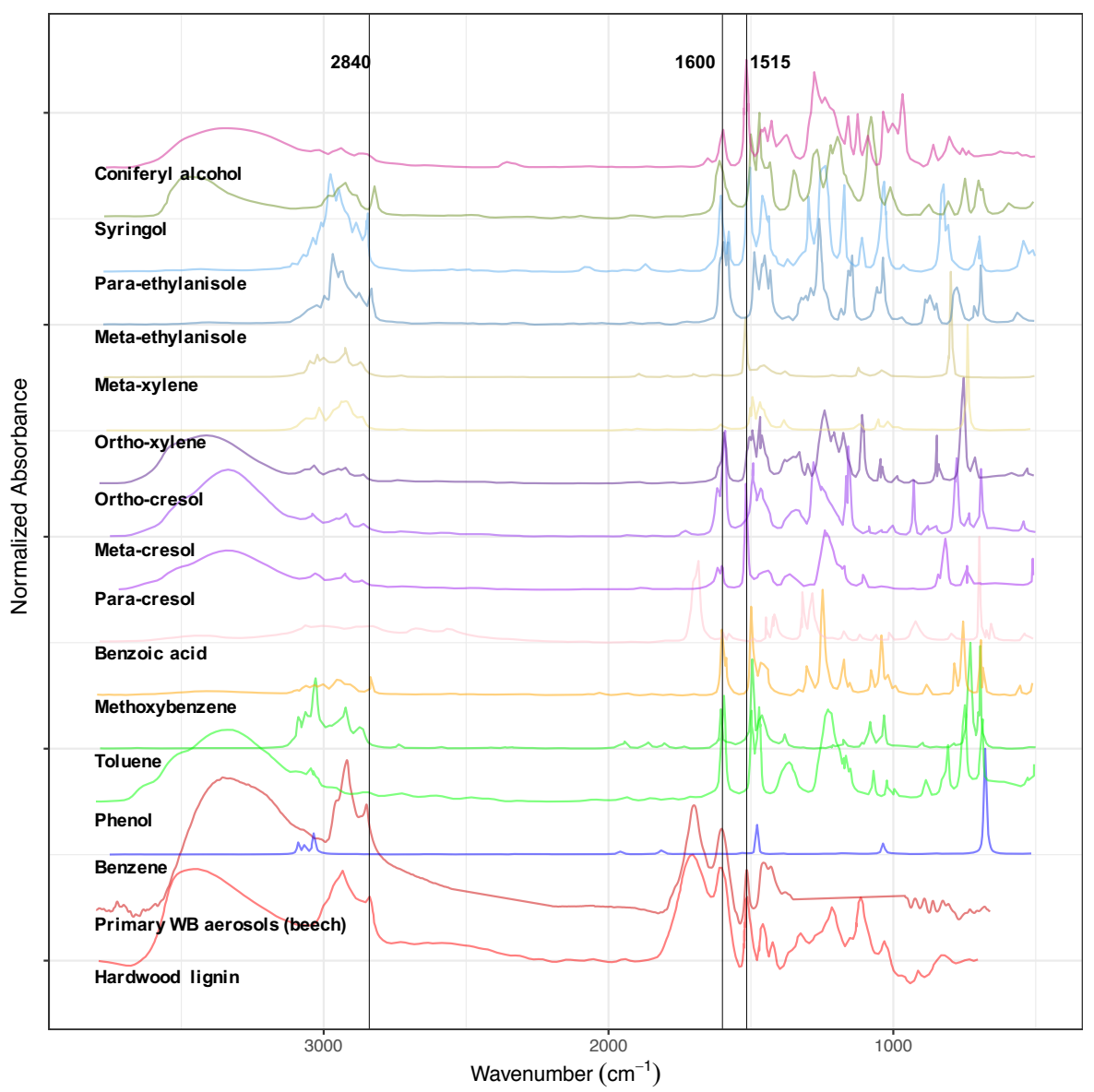

Figure S12. MIR spectra of hardwood lignin (KBr Pellet) from Boeriu et al. (2004), fresh beech wood burning aerosols (this work), coniferyl alcohol (film) from Boeriu et al. (2004), and some other substituted aromatic compounds (neat) from SpectraBase database (https://spectrabase.com/).

The peak at $1515 \mathrm{~cm}^{-1}$ is correlated with the AMS $\mathrm{C}_{8} \mathrm{H}_{9} \mathrm{O}_{2}{ }^{+}$fragment $\left(R^{2}=0.68\right)$, which is attributed $\mathrm{G}$ lignin fragmen55 tation (Tolbert and Ragauskas, 2017; Saito et al., 2005).

\section{S8 Atmospheric smoke impacted samples}




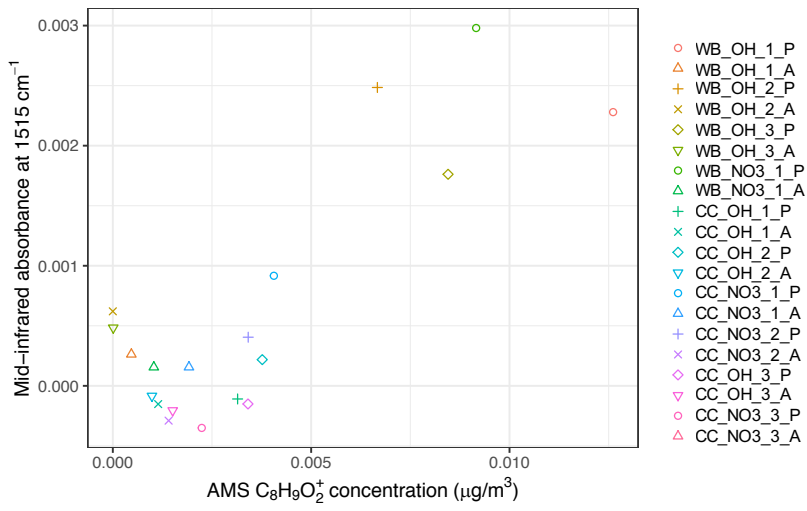

Figure S13. Scatter plot comparing the MIR $1520 \mathrm{~cm}^{-1}$ peak absorbance, attributed to lignin, and the $\mathrm{AMS}_{8} \mathrm{H}_{9} \mathrm{O}_{2}+$ fragment ion concentration averaged over the filter sampling periods $\left(R^{2}=0.68\right)$.

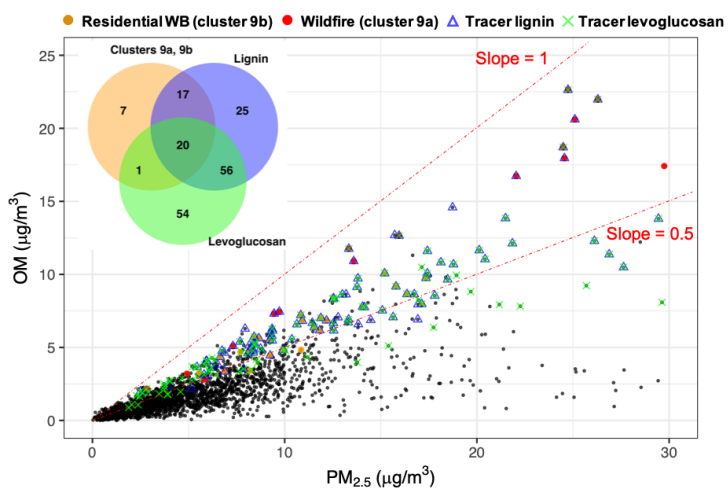

Figure S14. Scatter plot comparing total $\mathrm{PM}_{2.5}$ and OM mass in atmospheric samples. Orange and red circles indicate residential wood burning and wildfire samples identified by cluster analysis (Bürki et al., 2020), respectively. Blue triangles and green crosses shows burning samples identified based on lignin and levoglucosan signatures, respectively. Black circles indicate the existing atmospheric samples in the IMPROVE network (2011 and 2013; approximately 3050 samples). The dotted dashed lines delineate the range of OM mass fraction for samples designated as burning-influenced (the slope of 0.5 is arbitrarily chosen to guide the eye). OM was estimated by multiplying OC by 1.8 (assuming an average OM:OC ratio of 1.8). The Venn diagram at the top left compares the burning samples identified by each method.

\section{References}

Aiken, A. C., Salcedo, D., Cubison, M. J., Huffman, J. A., DeCarlo, P. F., Ulbrich, I. M., Docherty, K. S., Sueper, D., Kimmel, J. R., Worsnop, D. R., Trimborn, A., Northway, M., Stone, E. A., Schauer, J. J., Volkamer, R. M., Fortner, E., de Foy, B., Wang, J., Laskin, A., Shutthanandan, V., Zheng, J., Zhang, R., Gaffney, J., Marley, N. A., Paredes-Miranda, G., Arnott, W. P., Molina, L. T., Sosa, G., and Jimenez, J. L.: Mexico City Aerosol Analysis during MILAGRO Using High Resolution Aerosol Mass Spectrometry at the Urban Supersite (T0) - Part 1: Fine Particle Composition and Organic Source Apportionment, Atmos. Chem. Phys., p. $21,2009$.

Boeriu, C. G., Bravo, D., Gosselink, R. J. A., and van Dam, J. E. G.: Characterisation of Structure-Dependent Functional Properties of Lignin with Infrared Spectroscopy, Ind. Crops Prod., 20, 205-218, https://doi.org/10.1016/j.indcrop.2004.04.022, 2004.

65 Bruns, E., Krapf, M., Orasche, J., Huang, Y., Zimmermann, R., Drinovec, L., Močnik, G., El-Haddad, I., G. Slowik, J., Dommen, J., Baltensperger, U., and Prevot, A.: Characterization of Primary and Secondary Wood Combustion Products Generated under Different Burner Loads, Atmos. Chem. Phys., 15, 2825-2841, https://doi.org/10.5194/acp-15-2825-2015, 2015. 


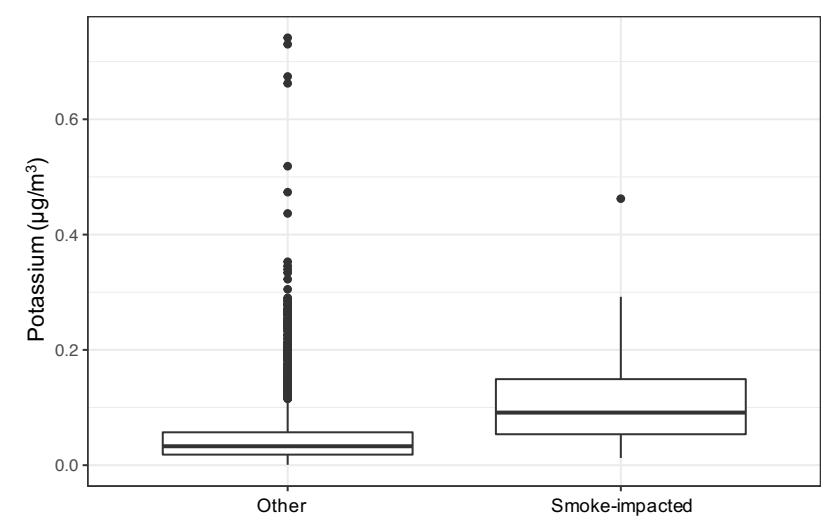

Figure S15. Box plot comparing potassium concentration of smoke-impacted and non-smoke-impacted samples in the IMPROVE network from X-ray fluorescence measurements.

Bürki, C., Reggente, M., Dillner, A. M., Hand, J. L., Shaw, S. L., and Takahama, S.: Analysis of Functional Groups in Atmospheric Aerosols by Infrared Spectroscopy: Method Development for Probabilistic Modeling of Organic Carbon and Organic Matter Concentrations, Atmos. Meas. Tech., 13, 1517-1538, https://doi.org/10.5194/amt-13-1517-2020, 2020.

Elser, M., Huang, R.-J., Wolf, R., Slowik, J. G., Wang, Q., Canonaco, F., Li, G., Bozzetti, C., Daellenbach, K. R., Huang, Y., Zhang, R.,

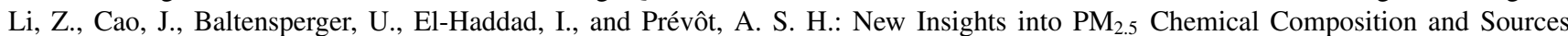
in Two Major Cities in China during Extreme Haze Events Using Aerosol Mass Spectrometry, Atmos. Chem. Phys., 16, 3207-3225, https://doi.org/10.5194/acp-16-3207-2016, 2016.

75 Faber, P., Drewnick, F., Bierl, R., and Borrmann, S.: Complementary Online Aerosol Mass Spectrometry and Offline FT-IR Spectroscopy Measurements: Prospects and Challenges for the Analysis of Anthropogenic Aerosol Particle Emissions, Atmos. Environ., 166, 92-98, https://doi.org/10.1016/j.atmosenv.2017.07.014, 2017.

Hennigan, C. J., Sullivan, A. P., Collett, J. L., and Robinson, A. L.: Levoglucosan Stability in Biomass Burning Particles Exposed to Hydroxyl Radicals, Geophys. Res. Lett., 37, https://doi.org/10.1029/2010GL043088, 2010.

80 McLafferty, F. W. and Tureček, F.: Interpretation of Mass Spectra, vol. 8, University Science Books, Mill Valley, CA, USA, fourth edn., 1993.

Pavia, D. L., Lampman, G. M., Kriz, G. S., and Vyvyan, J. A.: Introduction to Spectroscopy, Brooks Cole, Belmont, CA, fourth edn., 2008.

Russell, L. M., Bahadur, R., Hawkins, L. N., Allan, J., Baumgardner, D., Quinn, P. K., and Bates, T. S.: Organic Aerosol Characterization by Complementary Measurements of Chemical Bonds and Molecular Fragments, Atmos. Environ., 43, 6100-6105, https://doi.org/10.1016/j.atmosenv.2009.09.036, 2009.

Ruthenburg, T. C., Perlin, P. C., Liu, V., McDade, C. E., and Dillner, A. M.: Determination of Organic Matter and Organic Matter to Organic Carbon Ratios by Infrared Spectroscopy with Application to Selected Sites in the IMPROVE Network, Atmos. Environ., 86, 47-57, https://doi.org/10.1016/j.atmosenv.2013.12.034, 2014.

Saito, K., Kato, T., Takamori, H., Kishimoto, T., and Fukushima, K.: A New Analysis of the Depolymerized Fragments of Lignin Polymer Using ToF-SIMS, Biomacromolecules, 6, 2688-2696, https://doi.org/10.1021/bm050147o, 2005.

Schneider, J., Weimer, S., Drewnick, F., Borrmann, S., Helas, G., Gwaze, P., Schmid, O., Andreae, M. O., and Kirchner, U.: Mass Spectrometric Analysis and Aerodynamic Properties of Various Types of Combustion-Related Aerosol Particles, Int. J. Mass Spectrom., 258, 37-49, https://doi.org/10.1016/j.ijms.2006.07.008, 2006.

Tolbert, A. and Ragauskas, A. J.: Advances in Understanding the Surface Chemistry of Lignocellulosic Biomass via Time-of-Flight Secondary Ion Mass Spectrometry, Energy Sci. Eng., 5, 5-20, https://doi.org/10.1002/ese3.144, 2017. 